\title{
Accuracy of the RoPE score to estimate the size of a patent foramen oval as evaluated by transcranial Doppler with bubble study
}

Mariana Vargas, Fátima Soares, Vitor Oliveira,Ana Catarina Fonseca

Department of Neurosciences, Stroke Unit, Hospital de Santa Maria, University of Lisbon, Portugal

\section{Introduction}

Recent clinical trials have shown that patients with a large Patent Foramen Ovale (PFO) are the ones who benefit the most from PFO closure. The Risk of paradoxical Embolism Score (RoPE) is a tool used in cryptogenic stroke patients to ascertain the likelihood that a PFO is pathogenically related to the index stroke.

Some published models of therapeutic decision have suggested PFO closure when the RoPE score is $\geq 6$. RoPE Score consists of the following variables:

\begin{tabular}{l|l|}
\hline Patient characteristics & Points \\
\hline No history of hypertension & +1 \\
\hline No history of diabetes & +1 \\
No history of stroke or TIA & +1 \\
Nonsmoker & +1 \\
Cortical infarct on imaging +1 & +1 \\
\hline Age & \\
\hline $18-29$ & +5 \\
$30-39$ & +4 \\
\hline $40-49$ & +3 \\
$50-59$ & +2 \\
$60-69$ & +1 \\
$\geq 70$ & +0 \\
\hline
\end{tabular}

\section{Results}

343 Patients with cryptogenic stroke

II $8(34 \%)$ had a shower/curtain pattern

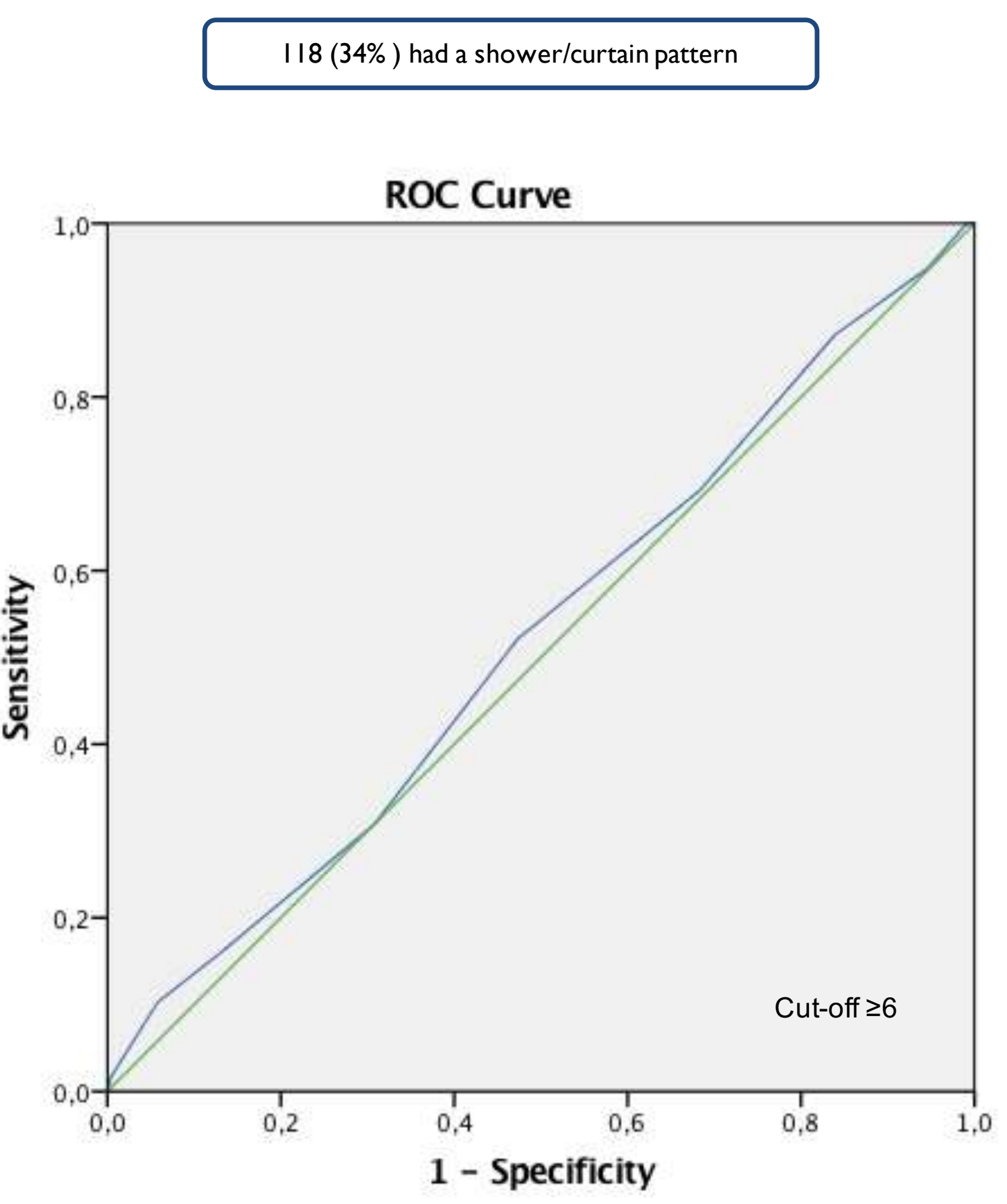

Aim

We seek to evaluate whether there is an association between the RoPE score and the size of the right-to-left shunt as evaluated by transcranial Doppler with bubble study.

\section{Materials and Methods}

We retrospectively analyzed consecutive patients with cryptogenic stroke that underwent transcranial Doppler with bubble study at an university hospital between 2016-2017. We collected data regarding demographics, components of the ROPE score and quantification of the shunt size by transcranial Doppler. A large shunt was defined as the presence of at least a curtain pattern,. ROC curve and Cstatistics were obtained. Statistical significance was set at $\mathrm{p}<0.05$

\begin{tabular}{|l|l|l|l|}
\hline Cut-off point: & ROPE $\geq \mathbf{6}$ & ROPE $\geq 7$ & ROPE $\geq \mathbf{8}$ \\
\hline Sensitivity \% (95\% CI) & $\begin{array}{l}52.1 \% \\
{[46.8 \%-57.4 \%]}\end{array}$ & $\begin{array}{l}30.8 \% \\
{[25.9 \%-35.7 \%]}\end{array}$ & $\begin{array}{l}16.2 \% \\
{[12.3 \%-20.1 \%]}\end{array}$ \\
\hline & & & \\
\hline Specificity \% (95\% CI) & $52.7 \%$ & $69.2 \%$ & $86.6 \%$ \\
\hline & {$[47.4 \%-58 \%]$} & {$[64.3 \%-74 \%]$} & {$[83 \%-90.2 \%]$} \\
\hline $\begin{array}{l}\text { Positive Predictive Value \% } \\
\text { (95\% CI) }\end{array}$ & $36.5 \%$ & $34.2 \%$ & $38.8 \%$ \\
\hline & {$[31.4 \%-41.6 \%]$} & {$[29.2 \%-39.2 \%]$} & {$[33.6 \%-44 \%]$} \\
\hline
\end{tabular}

Negative Predictive Value \% $(95 \%$ CI)

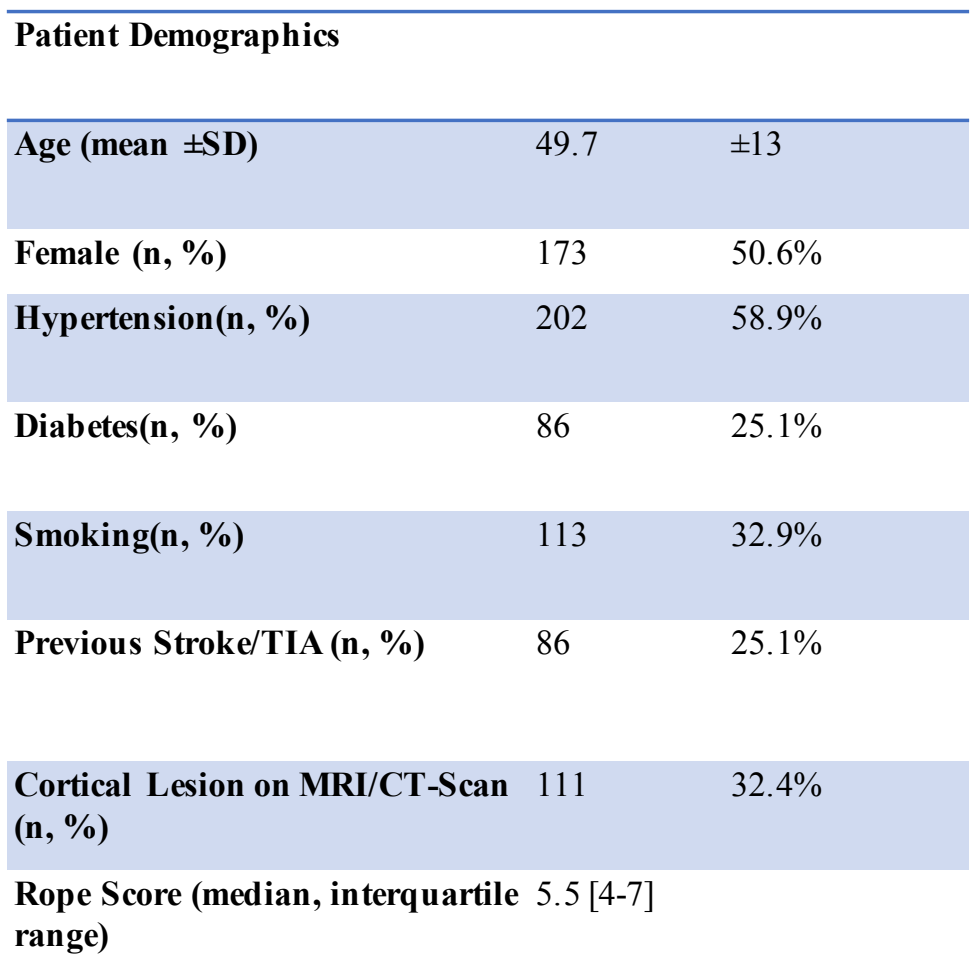

C statistic: $0.52(95 \%[\mathrm{Cl}], 0.46-0.59)$

\section{Discussion:}

RoPE Score had a low accuracy for the detection of an hemodynamically significant PFO on transcranial Doppler examination. 